Article

\title{
Finding Common Ground between United Kingdom Based and Chinese Approaches to Earthen Heritage Conservation
}

\author{
Jenny Richards * (D), Yinghong Wang, Scott A. Orr ${ }^{\mathbb{D}}$ and Heather Viles \\ School of Geography and the Environment, University of Oxford, Oxford OX1 3QY, UK; \\ yinghong.wang@ouce.ox.ac.uk (Y.W.); scott.orr@ouce.ox.ac.uk (S.A.O.); heather.viles@ouce.ox.ac.uk (H.V.) \\ * Correspondence: jennifer.richards@ouce.ox.ac.uk; Tel.: +44-(0)1865-285070
}

Received: 25 July 2018; Accepted: 28 August 2018; Published: 30 August 2018

\begin{abstract}
Earthen heritage is one of the oldest and universal forms of heritage but its conservation poses many challenges. Establishing international collaborations could provide an efficient, sustainable mechanism to increase knowledge exchange, aiding the development of earthen heritage conservation strategies around the world. However, perceived differences in how Eastern and Western countries value earthen heritage and develop conservation strategies can pose challenges for establishing collaborations. To understand these perceived differences and whether they hinder collaborations, this paper compares British and Chinese heritage conservation policy and practice and then reports the results from an innovative workshop examining the approaches of 13 Chinese and 13 UK based heritage experts and researchers towards earthen heritage conservation. Workshop participants undertook bilingual discussions and completed a co-created questionnaire available in English and Mandarin. Both groups identified historic value as the most important value and maintenance of authenticity and integrity, need for scientific research and site scale conservation as vital considerations for conservation strategies. This study found that to understand the potential for collaboration, individual perspectives need consideration as well as policies and practices. This innovative bilingual, discussion-based approach has potential to aid collaborations for diverse international issues from wildlife conservation to cross-boundary pollution and climate change.
\end{abstract}

Keywords: earthen heritage; conservation; collaboration; policy; practice; bilingual; discussion; cross-cultural

\section{Introduction}

Earthen heritage is one of the oldest and universal forms of heritage with sites dating back to Neolithic times [1-3]. Its global importance has been recognized with earthen heritage comprising $10 \%$ of World Heritage Sites [4]. The first international Terra conference took place in 1972 which addressed the protection of earthen heritage and the establishment of national and international networks [2]. Interest in earthen heritage conservation has developed rapidly since the 1990's with research now being undertaken worldwide [5-7]. Nevertheless, earthen heritage conservation still faces many challenges caused by a lack of research into earthen materials [8]; the vulnerability of earthen materials to degradation by environmental processes [4,9]; and the locations of many sites in remote and/or politically fragile areas [4]. The implication of these challenges is seen with earthen heritage sites comprising $33 \%$ of the World Heritage in danger list [4].

Earthen heritage conservation and research has been and continues to be strongly directed and influenced by heritage conservation policies and past practice. International heritage conservation policy has developed since the late 1870 's through a series of international charters, recommendations, 
resolutions and declarations [10] as well as through the development of domestic polices and guidelines. Until the 1980's and 1990's, the vast majority of the international documents and heritage conservation practice were based on Western heritage sites and Western approaches to heritage conservation (e.g., Charter of Athens, 1933, The Venice Charter, 1964 and the European Charter of Architectural Heritage, 1975) but applied globally. It was not until the publication of documents such as The Nara Document on Authenticity (1994), that Eastern approaches to heritage conservation were explicitly addressed in built heritage conservation policy. However, Western biases still have the potential to brush over the vast range of heritage conservation practices. When addressing collaborations between Eastern and Western countries, understanding and acknowledging these historic biases is important as notions of an east/west divide can further mask important nuances in conservation practice [11]. Furthermore, as countries subscribe to international policies, countries have autonomy over conservation practices but this means there is a lack of an overarching international heritage conservation policy and so many approaches have been developed for earthen heritage conservation. Previous research has compared heritage conservation policies and past practices to understand the extent of differences, if any, between Eastern and Western countries [10,12-15]. However, despite the worldwide importance of earthen heritage and a great diversity of approaches to its conservation, there have been few studies addressing this specifically for earthen heritage [16].

Earthen heritage conservation research has tended to develop strategies which can be applied to the physical structure of walls and reduce rates of degradation from environmental processes (e.g., wind, precipitation, sediment erosion) or to minimize damage caused by earthquakes. For sites located in low risk areas for earthquakes, strategies to reduce the impact of degradation caused by environmental processes include:

- applying surface treatments such as stabilizers [17,18], additives [19] and consolidants [20-22].

- placing wall caps made of concrete, terracotta and tiling as well as soil and vegetation on top of earthen walls to be used as a sacrificial layer and promote water run off away from the wall $[5,23,24]$.

- $\quad$ adding drainage systems such as surface drains [25], drainage slopes [26,27], drainage pipes [28,29] and damp proof coursing [30] to promote the movement of water away from the site.

- applying structural interventions such as grouting cracks and wooden rod anchorages to the walls [31].

In general, these approaches have initially decreased rates of erosion but over longer time periods, they have tended to have minimal impact $[18,21,32]$ or, in some cases, have increased rates of degradation by causing unintended consequences such as salt mobilization and water pooling [23,33]. The complexity of deteriorative processes impacting earthen heritage suggests that new techniques and approaches need to be researched and trialled to minimize further damage to earthen heritage.

To aid future research into earthen heritage conservation, establishing international collaborations is vital for forming sustainable mechanisms for promoting knowledge sharing and understanding [6,15]. There have previously been several such collaborations [12,34]. However, perceived differences, especially between Western and Eastern countries, in how countries value heritage sites and implement conservation strategies as well as language and geographical barriers, have made collaborations difficult $[10,12,35]$, suggesting that further attempts to elicit common values and approaches towards heritage conservation are required for collaboration to be successful. These perceived differences are seen between the UK and China which have different histories regarding heritage conservation [10]. However, both countries are at the forefront of research on earthen heritage and heritage science more generally, have comprehensive heritage conservation policies and have shown a desire to undertake future collaborative work. This paper focuses on comparing specific countries, rather than wider continental approaches to conservation to allow a deeper discussion and understanding of potential collaboration between researchers. 
This study is part of a wider research project involving researchers in the UK and China using computational modelling to assess the suitability of conservation strategies for earthen heritage-focusing on the World Heritage earthen site of Suoyang Ancient City (锁阳城), Gansu Province, northwest China. As such, it is essential to understand why certain conservation strategies are implemented and whether ideas about what constitutes a preferred conservation strategy differ between countries. This study has three goals: (1) to compare heritage conservation policy and practice, past and present, in the UK and China to identify differences and similarities in formal principles/guidelines and to understand if and how, these differences have played out in heritage conservation. (2) To assess more specifically the potential for future collaborations for earthen heritage conservation, through an investigation of the similarities and differences between small groups of UK based and Chinese experts with backgrounds in conservation practice and conservation and deterioration research. Heritage experts were chosen for this study as in both the UK and China they play a crucial role in developing new strategies and disseminating information to relevant bodies who implement conservation strategies $[6,14,35]$. Experts from a range of ages and academic positions were included to assess the current potential for collaboration as well as incorporating the views of early career researchers to understand potential future trajectories for collaboration within earthen heritage research. (3) To understand if differences between policy and practice in the UK and China map onto those recorded from the in-depth exploration of UK based and Chinese experts.

\section{Materials and Methods}

\subsection{Comparison of Policies and Practices}

National policy documents were chosen for comparison due to the lack of overarching international principles for earthen heritage conservation (Figure 1). Principles for the Conservation of Heritage Sites in China, 2015, (hereafter the China Principles) and Historic England's Conservation Principles, Policies and Guidance, 2008, (hereafter Historic England's Conservation Principles) where chosen as both documents are comprehensive and have a national influence over the undertaking of heritage conservation.

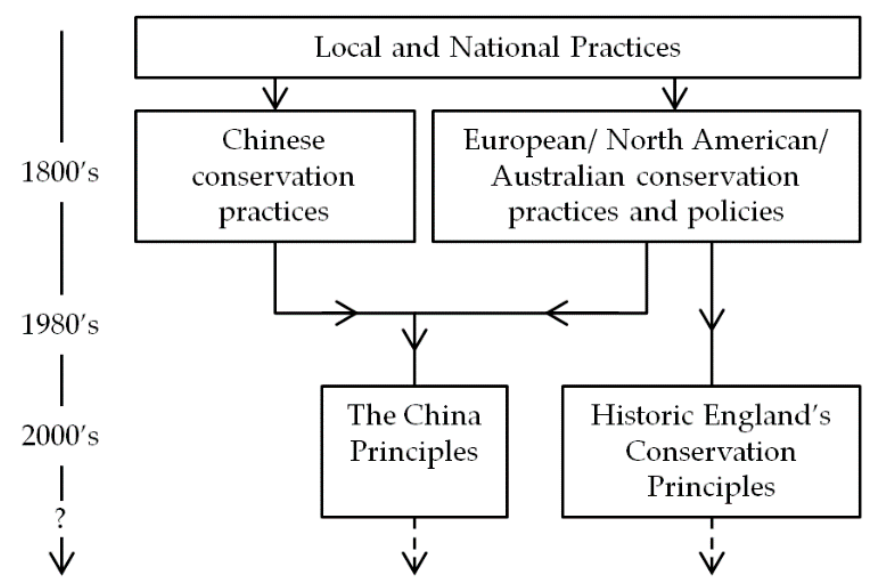

Figure 1. The development of the China Principles and Historic England's Conservation Principles from regional practices and policies.

In England, Historic England's Conservation Principles provide a framework for conservation practices and managing change in historic environments [36]. In China, Principles for the Conservation of Heritage Sites in China, 2015, (hereafter the China Principles) provide national guidelines for cultural heritage practice [37]. The China Principles were originally produced in 2000 through collaboration between China, Australia and America (Figure 1). It has since been published bilingually 
with a Mandarin/English glossary of technical terms and concepts to ensure consistent usage of terminology [35] and was revised in 2015. This study uses the 2015 version. Both policies were thematically reviewed and compared.

To compare past heritage conservation practices, a wide literature search including both English and Chinese publications was undertaken for each of the main themes identified in the policies. The search was not limited to earthen heritage to ensure a broad range of heritage practices were assessed and compared.

\subsection{Approach to the Workshop}

The workshop element of this study was carried out as part of a larger two-day workshop held in March 2018 in the UK. The workshop was attended by 13 Chinese and 13 UK based heritage experts and scientific researchers who undertake work to inform and shape conservation strategies and who have a range of academic and practical experience. The UK based participants were international in profile but as they were working in the UK they are seen as representing current UK approaches to heritage research. All participants had a minimum of a master's degree with over half also having a doctorate and were from a range of career stages from early career, with approximately $25 \%$ of participants under 30 years old, to senior researchers.

The workshop was bilingual throughout to recognize the importance of language in communicating technical and nuanced ideas. All resources were available in Mandarin and English and were translated by a researcher who has studied heritage science at a post graduate level in both China and the UK. Additionally, three translators were present to translate introductory presentations, feedback and questions.

At the start of the workshop, all participants were invited to introduce themselves, their work and their background. At the start of every session, the importance of everyone's contribution to the discussions was emphasized. All sessions were held under Chatham House rules to protect participants' anonymity (see www.chathamhouse.org for more information).

The workshop used a mixed method approach to enable the collection of qualitative and quantitative data. Discussions were used to gain a deeper understanding of how participants approached the valuation of earthen heritage sites and its conservation. The discussions also allowed participants the freedom to express and discuss individual views, ask questions and debate contentious topics. A co-created questionnaire completed anonymously was used to ensure that all participants had the opportunity to express their views and all responses were viewed as equal. It also allowed the collection of quantifiable data.

\subsection{Workshop Case Study: Suoyang Ancient City}

To focus discussions, Suoyang Ancient City was used as a case study site. Suoyang Ancient City was built in the Han and Tang dynasties along the Silk Road in northwest China, to the north of the Qilian Mountains (Figure 2). It was built largely out of rammed earth as a fortification and communication settlement and also had an extensive irrigation infrastructure. In 2014, it was listed as one of 33 properties that make up the trans-boundary Silk Road World Heritage site.

A Chinese earthen heritage site was chosen as a focus for discussion to move away from the historic Western bias seen in conservation policy and practice. Suoyang was chosen as many of the Chinese researchers and some of the UK based researchers had visited the site. Furthermore, Suoyang is experiencing degradation by wind, sediment and water erosion but lacks a comprehensive long-term conservation plan, thus it provides real conservation challenges that could be discussed throughout the workshop.

An introductory presentation about Suoyang was given to ensure all participants had a baseline knowledge of Suoyang and its conservation challenges. For those who had not visited the site, they were asked to use their knowledge of other earthen heritage sites throughout the workshop. 


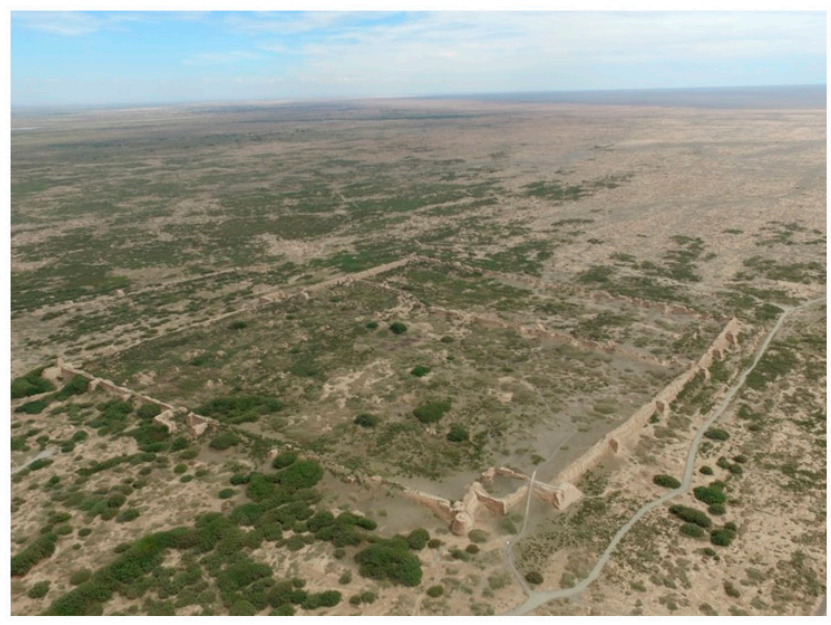

(a)

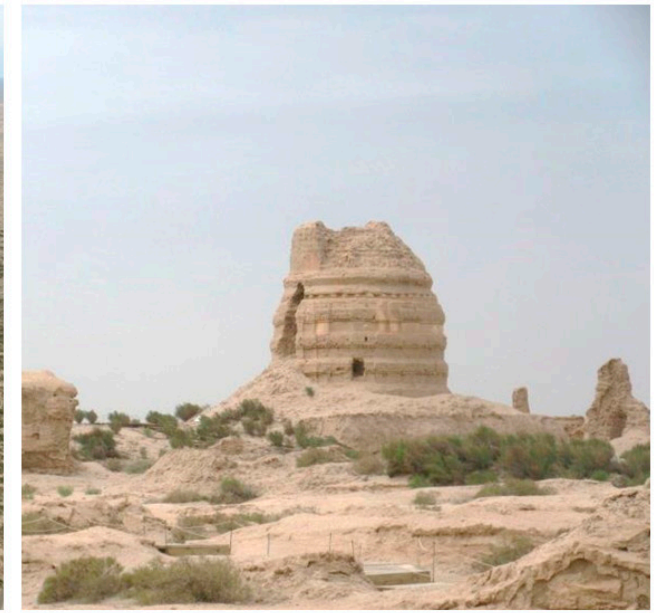

(b)

Figure 2. The site of Suoyang Ancient City showing (a) the inner-city walls (photo credit: Dunhuang Academy) and (b) the Ta'er temple (photo: author's own).

\subsection{Discussions}

Discussions were held in four groups of 5 to 7 people. Each group had a chairperson and a note taker. Note takers did not attribute any comments to specific participants. The groups were organized such that there were two UK based and two Chinese groups. All groups had researchers from a range of ages, academic levels and backgrounds and where possible, an equal gender balance. This was chosen after consultation with Chinese and UK based researchers to allow discussion to flow freely within the time available and to ensure participants felt able to present their own views.

There were three discussions which each lasted between 20 to $35 \mathrm{~min}$. The topics for discussion were developed with input from both UK based and Chinese heritage researchers to ensure all participants could contribute. The discussions focused on (1) values associated with Suoyang; (2) factors which need to be considered in designing a conservation strategy; and (3) which aspects of a conservation strategy are the most/least important and which are difficult to implement. At the end of each discussion session, the group chairs fed back to all participants and there was time for questions.

After the third discussion, participants were given six post-it notes, each divided in two with English and Mandarin sections. Participants wrote their three most important and three least important factors for a conservation strategy for earthen heritage and answers were translated. These were bought to the front and arranged into themes.

\subsection{Questionnaire}

The thematic review of the policy documents and earthen heritage literature was used to create a baseline questionnaire. The questionnaire was designed to gain an insight into (1) how participants value Suoyang and earthen heritage and (2) what participants would view as a preferred conservation strategy. The questionnaire was presented in both Mandarin and English at the workshop for discussion (Figure 3). Participants were asked to critique the questionnaire, assessing if questions were relevant and if all key aspects of earthen heritage conservation were addressed. In addition, this process allowed participants to clarify parts of the questionnaire which may have been open to misinterpretation. Suggestions to alter the baseline questionnaire were made by both Chinese and UK based participants with questions being added, removed and redefined. These suggestions were used to produce a co-created questionnaire available in both Mandarin and English (Figure 3). 


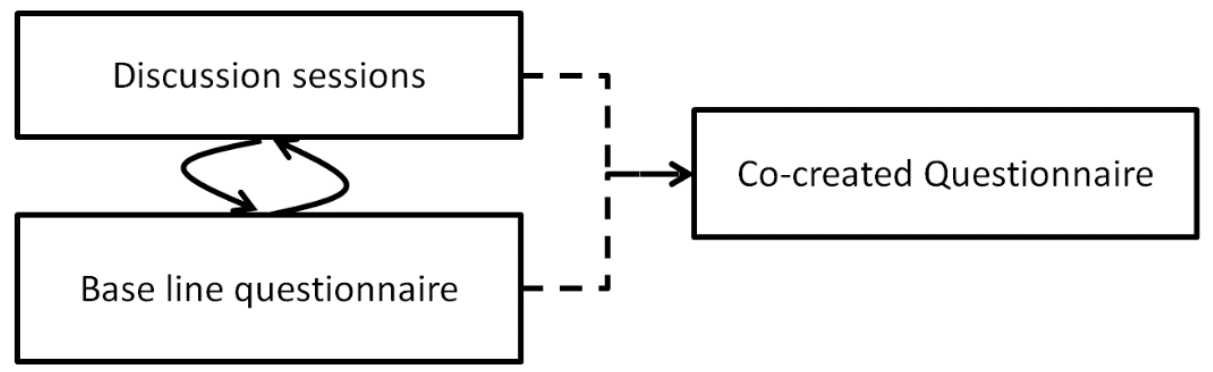

Figure 3. The processes of producing the co-created questionnaire.

The final co-created questionnaire contained six questions on value, 28 questions on what constitutes a preferred conservation strategy and three optional demographic questions (Table 1). Within the final questionnaire were six question types (see Table 1 and Appendix A). The three most common types were:

- A five-point Likert-type scale used for value questions. The scale ranged from 1 (not important) to 5 (very important) with 3 as neutral.

- An adapted seven-point semantic differential/Likert-type scale with true opposites used for questions relating to conservation strategies. Pairs of mutually exclusive words, such as 'visible' and 'not visible,' were placed at the left and right ends of a horizontal scale. The scale ranged from 3 (left hand side concept is essential) to 0 (neutral) to 3 (right hand side concept is essential).

- An adapted seven-point semantic differential, Likert-type scale with false opposites. This differed from the previous question type as the pairs of words at the opposite ends of the scale were not mutually exclusive. This question type was included to force the respondents to think whether they had a preference towards one option. If both were of equal importance, the participant would choose 0 .

With all scales, intermediary numbers did not have word descriptions to produce more equal spacing between numbers. All participants were given as much time as they needed to complete the questionnaire which on average took 15 to $20 \mathrm{~min}$.

Table 1. Questions and possible answers included in the questionnaire.

\begin{tabular}{|c|c|c|c|}
\hline Question Type & Question Number & Factor Assessing & Possible Answers \\
\hline & & Values & \\
\hline \multirow{3}{*}{ Likert-type scale (1-5) } & A & Historic value & 1 (Not important)- 5 (Very important) \\
\hline & $\mathrm{C}$ & Artistic value & 1 (Not important)-5 (Very important) \\
\hline & $\mathrm{D}$ & Social value & 1 (Not important)-5 (Very important) \\
\hline \multicolumn{4}{|c|}{ Conservation strategy considerations } \\
\hline \multirow{4}{*}{ Multiple choice (tick one) } & 1 & Application area of strategy & $\begin{array}{l}\text { Do nothing; Main body of the wall; Wall foundations; } \\
\text { Surrounding environment }\end{array}$ \\
\hline & 2 & $\begin{array}{l}\text { Location to } \\
\text { reduce degradation }\end{array}$ & $\begin{array}{l}\text { Areas experiencing degradation; Areas at future risk; Areas } \\
\text { experiencing and at risk of degradation; All areas of the site }\end{array}$ \\
\hline & $15 b$ & $\begin{array}{l}\text { Minimal people hours } \\
\text { for installation }\end{array}$ & $<50 \mathrm{~h} ; 50-200 \mathrm{~h} ; 200-1200 \mathrm{~h} ; 1200-2400 \mathrm{~h} ;>2400 \mathrm{~h}$ \\
\hline & $16 \mathrm{~b}$ & $\begin{array}{l}\text { Minimal people hours for } \\
\text { monthly maintenance }\end{array}$ & $<1 \mathrm{~h} ; 1-10 \mathrm{~h} ; 10-50 \mathrm{~h} ; 50-100 \mathrm{~h} ;>100 \mathrm{~h}$ \\
\hline
\end{tabular}


Table 1. Cont.

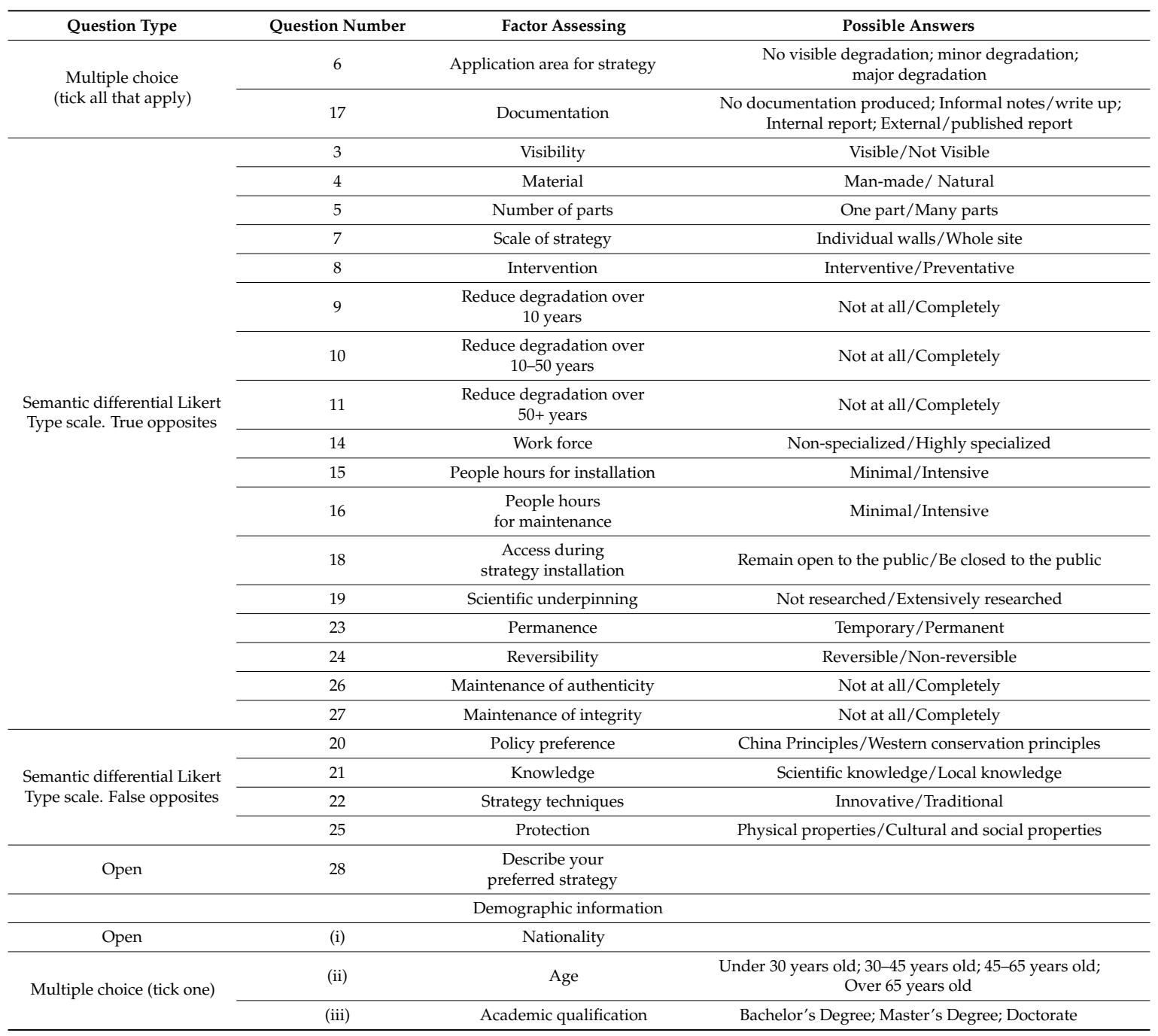

Analysis of Questionnaire Results

Results from the discussion were reviewed thematically and results from the questionnaire were analysed dependent on question type.

Relative Importance Index (RII) was used to assess the strength of opinions from scalar questions. RII is a non-parametric test which can be used on ordinal data (Appendix B) [38]. The index ranges from 0 to 1 but the meaning of the RII value is dependent on the scale of the question type used (Table 2). For the seven-point semantic differential, Likert-type scales, a high RII value could be caused by either all respondents answering highly on the same side of the scale or by respondents answering highly on different sides of the scale.

To test for the agreement between participant responses, a weighted agreement index was developed by the authors for the seven-point semantic differential, Likert-type scales (Appendix B). The index ranges from -1 to 1 with 1 showing that all participant responses were on the right-hand side of the scale and -1 showing that all respondents responded on the left-hand side of the scale. As the index tends towards 0 , there was less agreement among respondents. Neutral responses were not included as they had not shown a preference to either side of the scale.

To compare the difference in responses between Chinese and UK based responses, Mann-Whitney $\mathrm{U}$ test was used at a 0.05 level of significance. 
Table 2. The meaning of Relative Importance Index (RII) values for three question types.

\begin{tabular}{cccc}
\hline & Five-Point Likert-Type Scales & $\begin{array}{c}\text { Seven-Point Semantic Differential, } \\
\text { Likert-Type Scales with True Opposites }\end{array}$ & $\begin{array}{c}\text { Seven-Point Semantic Differential, } \\
\text { Likert-Type Scales with False Opposites }\end{array}$ \\
\hline $\mathbf{x} \rightarrow \mathbf{0}$ & Heritage value not important & Ambivalence towards conservation factor & $\begin{array}{c}\text { Important to consider factors on both } \\
\text { sides of scale }\end{array}$ \\
\hline $\mathbf{x}=\mathbf{0 . 5}$ & Ambivalence towards heritage value & & \\
\hline $\mathbf{x} \rightarrow \mathbf{1}$ & Heritage value very important & Factor of conservation strategy is essential & Factor of conservation strategy is essential \\
\hline
\end{tabular}

\section{Results}

\subsection{Policy and Practice Comparisons}

\subsubsection{Policy}

The China Principles and Historic England's Conservation Principles were found to have many similarities but also some differences in key concepts which could impact on how earthen heritage conservation is undertaken (Table 3). The China Principles regard heritage sites as places with "immovable physical remains created during the history of humankind and that have significance" [37] (p. 58). They also state that the aim of heritage conservation is "to preserve all physical evidence" along with its intangible heritage and to slow future deterioration [37] (p. 61). In contrast, Historic England's Conservation Principles place a much stronger weighting on intangible heritage as they view heritage sites as going beyond the physical to include all characteristics that can contribute to a sense of place [36] (p. 14) and heritage conservation as the process of managing change in ways that will sustain the site's values [36] (Principle 4.2). Current earthen heritage conservation research focuses mainly on protecting physical structures but even though the publication of the China Principles placed a greater emphasis on intangible heritage in Chinese heritage conservation policy [35], the differences between the two sets of principles could cause friction over future considerations of intangible heritage within earthen heritage conservation.

Table 3. Comparison of key concepts in the China Principles (2015) and Historic England's Conservation Principles (2008).

\begin{tabular}{|c|c|c|}
\hline & China Principles & Historic England's Conservation Principles \\
\hline What is a heritage site? & $\begin{array}{l}\text { Immovable physical remains created during the } \\
\text { history of humankind and have significance }\end{array}$ & $\begin{array}{l}\text { A site goes beyond the physical material to } \\
\text { include all characteristics that contribute to a } \\
\text { sense of place }\end{array}$ \\
\hline What is the aim of conservation? & $\begin{array}{l}\text { To preserve the existing condition and slow } \\
\text { deterioration to the site }\end{array}$ & $\begin{array}{l}\text { To manage change to a site that will } \\
\text { sustain its values }\end{array}$ \\
\hline Values & Historic, artistic, scientific, social and cultural & Historic, evidential, aesthetic and communal \\
\hline Authenticity & $\begin{array}{l}\text { Resides in original materials, } \\
\text { workmanship and design }\end{array}$ & $\begin{array}{l}\text { Attributes and elements that most } \\
\text { truthfully reflect and embody } \\
\text { the heritage values attached to it }\end{array}$ \\
\hline Integrity & $\begin{array}{l}\text { Preserving the entirety of a site } \\
\text { and full range of values }\end{array}$ & Wholeness and honesty \\
\hline Conservation techniques & $\begin{array}{l}\text { Only techniques proven to be beneficial to } \\
\text { reducing degradation at the site should be used. } \\
\text { Traditional craftsmanship should be maintained }\end{array}$ & $\begin{array}{l}\text { Traditional materials have known } \\
\text { lifetimes and behaviours whereas } \\
\text { new materials are much less certain }\end{array}$ \\
\hline Reversibility & $\begin{array}{l}\text { Conservation treatments should not } \\
\text { compromise future treatments }\end{array}$ & $\begin{array}{l}\text { Ability to judge long term impact } \\
\text { of changes is limited }\end{array}$ \\
\hline Participation & $\begin{array}{l}\text { The public have a responsibility and obligation to } \\
\text { participate in heritage conservation. All levels of } \\
\text { government are responsible for the conservation } \\
\text { of sites. Research should be encouraged }\end{array}$ & $\begin{array}{l}\text { Everyone should be able to participate } \\
\text { and stakeholders should be encouraged } \\
\text { to engage with sites } \\
\text { Experts should use knowledge } \\
\text { to encourage learning }\end{array}$ \\
\hline
\end{tabular}

Both sets of principles emphasize that conservation can only be successful when a site's values are understood. Values are classified in The China Principles as historic, artistic, scientific, social and cultural [37] (p. 61) and in Historic England's Conservation Principles as historic, evidential, aesthetic 
and communal [36] (pp. 28-32). Despite the different names attributed to value types, there is some overlap between meanings in the two policies (Figure 4). For example, Historic England's communal value derives meaning from people who relate to a site [36] (p. 31) and similarly the China Principles' social and cultural values relate to the benefit that society derives from a site and also the ethnic, regional and religious diversity associated with a site [37] (p. 61). Some values, such as artistic and aesthetic value, do not have an equivalent. In the China Principles, artistic value addresses the artistic creativity and the site's representative style of a particular period in history and in Historic England's Conservation Principles aesthetic value is derived from how people gain sensory and intellectual stimulation from a site. This suggests some value types can be approximately transferred between countries. However, care is needed to understand and preserve the nuanced differences between value types and furthermore, acknowledge that for some values, earthen sites are judged differently in different countries.

\begin{tabular}{ll}
\hline $\begin{array}{l}\text { China } \\
\text { Principles }\end{array}$ & $\begin{array}{l}\text { Historic England's } \\
\text { Conservation Principles }\end{array}$ \\
\hline Historic $\longleftrightarrow$ Historic \\
Scientific $<--->$ Evidential
\end{tabular}

Artistic

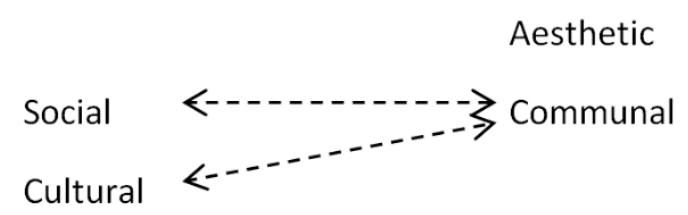

Figure 4. Comparison of values in China Principles (2015) and Historic England's Conservation Principles (2008). The solid arrow represents strong similarities between values. The dashed arrow represents some overlap between values.

Historic England's Conservation Principles view authenticity as a site's attributes and elements that most truthfully reflect and embody the heritage values attached to it [36] (Principle 4.3). Similarly, the China Principles view authenticity as residing in the original materials, workmanship and design along with the continuation of cultural traditions associated with the site [37] (p. 67). In both principles, reconstruction of extant sites is not permitted and any changes to a site should be distinguishable from original material. However, in the China Principles, there is a greater flexibility for reinstatement when the original site has for example partially collapsed, deformed or when reinstatement enables the historic setting to reveal the values of the site [12,39]. This difference in reinstatement could pose problems for earthen heritage conservation research with different standards being viewed as acceptable.

In both principles, integrity focuses on conserving the full range of a site's values within its setting. The China Principles place a heavy emphasis on the use of buffer zones which is also emphasized in UNESCO World Heritage nominations [12].

Both principles emphasize the use of traditional materials and advise against the use of new material until they have been proven effective. However, the China Principles state that conservation measures should not compromise future treatments [37] (p. 68) whereas Historic England's Conservation Principles state that it is difficult to judge the long-term impact of conservation treatments and this should not prevent modest changes being applied [36] (p. 47). For earthen heritage research, this means that both UK and China have a similar policy approach to the materials and 
methods to use in conservation strategies but China, adhering to the China Principles, could be more reserved when applying new treatments to sites.

Substantial differences were found over who can participate in the process of conservation. The China Principles are based on a top down approach where the national government holds the ultimate decision making power [6,35], all heritage practitioners are expected to follow them [12] and the public should feel a responsibility and obligation to support heritage conservation [37] (p. 64). In contrast, Historic England's Conservation Principles provide a framework to advise government but they are not dependent on the government's support and there is a greater emphasis on experts engaging and encouraging participation from communities and other stakeholders [36] (Principle 2). These differences in governance and participation within heritage conservation have the potential to cause frustrations and tensions within international collaborations while participants become familiar with other countries systems and appreciate their merits—even if they go against personal beliefs about how systems should be organized.

\subsubsection{Practice}

Despite many similarities between policies, multiple differences between heritage conservation practice in the UK and China have been found, caused in part by historical, cultural, political and practical differences $[10,12,40]$. According to reviews of conservation in China $[6,10,41]$, contemporary conservation practices which focus on conserving physical remains and historic material of sites were not established until the early 1900s and grew in popularity in the 1980s with the opening up of China. This means conservation practice is still relatively young in China and collaborations need to recognize the challenges caused by this, such as a lack of public awareness.

Cultural differences have also been found to cause differences in heritage conservation practice between the UK and China. For example, in practice, considerations of authenticity in the UK generally reflect Historic England's policy guidelines and are highly related to material concepts with preferences towards minimal intervention. Current understandings of authenticity in the UK developed over the course of the 19th century, with some suggesting that conflicting values surrounding cultural heritage caused the concept of authenticity to rise in importance and go from restoration and conservation being entwined ideas to focusing ideas found in its current definition [42]. In China, authenticity is viewed by some as an imported concept [43] and it is debated whether authenticity should conserve original parts of the site in their present day condition or, if sites should be restored to give the effect of how the site was at its prime as this is argued to give visitors a more authentic experience of visiting the site [44]. The discrepancy has occurred as authenticity is not an indigenous concept in China $[43,44]$ and so authenticity can either be translated in Mandarin as yuanzhenxing (原真性) meaning 'the original true state' or zhenshixing (真实性) meaning 'true state' [45]. If yuanzhenxing is used, this refers to the original state of the site when it was created thus supporting large scale reconstructions to recreate sites as they were in their heyday. If zhenshixing is used, the concept is applied to the current condition of the site. For earthen heritage research this means that those involved need to understand which version of authenticity is being used for the sites and what implications this has for the conservation strategy.

Differences in the governance of and participation in heritage conservation were also found. China's top down structure of governance of heritage conservation means that local voices are not effectively heard, although there has recently been an increased effort to include local groups in conservation strategies [46-48]. In comparison, many UK heritage conservation organizations encourage the inclusion of multiple stakeholders and communities when developing conservation strategies but tensions between expert and local knowledge are still found especially at the planning stage [49,50]. With different stakeholder groups being included in the conservation of different sites, collaborations need to be open about whose voices are heard and how this could affect decisions regarding the conservation of a site.

Finally, it is worth noting that there are also practical challenges for earthen heritage conservation caused by language and geographical barriers. Translating complex technical concepts requires far 
more than word for word translation as seen with the concept of authenticity [35,45]. It requires someone with a technical understanding of the topic in both languages to be able to translate concepts so they have the same meanings and connotations in both languages even when specific words may not exist in one or other of the languages. In addition, there is the challenge of overcoming the physical distance between collaborators. Internet based communication may be appropriate but in many cases setting up a collaboration as well as undertaking field or site work requires meeting in person. As the distance between China and the UK is vast and travel and visa applications are expensive, this requires enough funding to support such meetings.

\subsection{Workshop and Questionnaire Outcomes}

\subsubsection{Value}

Historical value was seen as Suoyang's most important value by both Chinese and UK based respondents with scientific and cultural values also being seen as important (Figure 5). There was general ambivalence towards Suoyang's artistic value. However, in the discussion some UK based participants viewed the site and especially the temple, as beautiful while some actively viewed the sites as lacking artistic value due to its lack of decoration and embellishment.

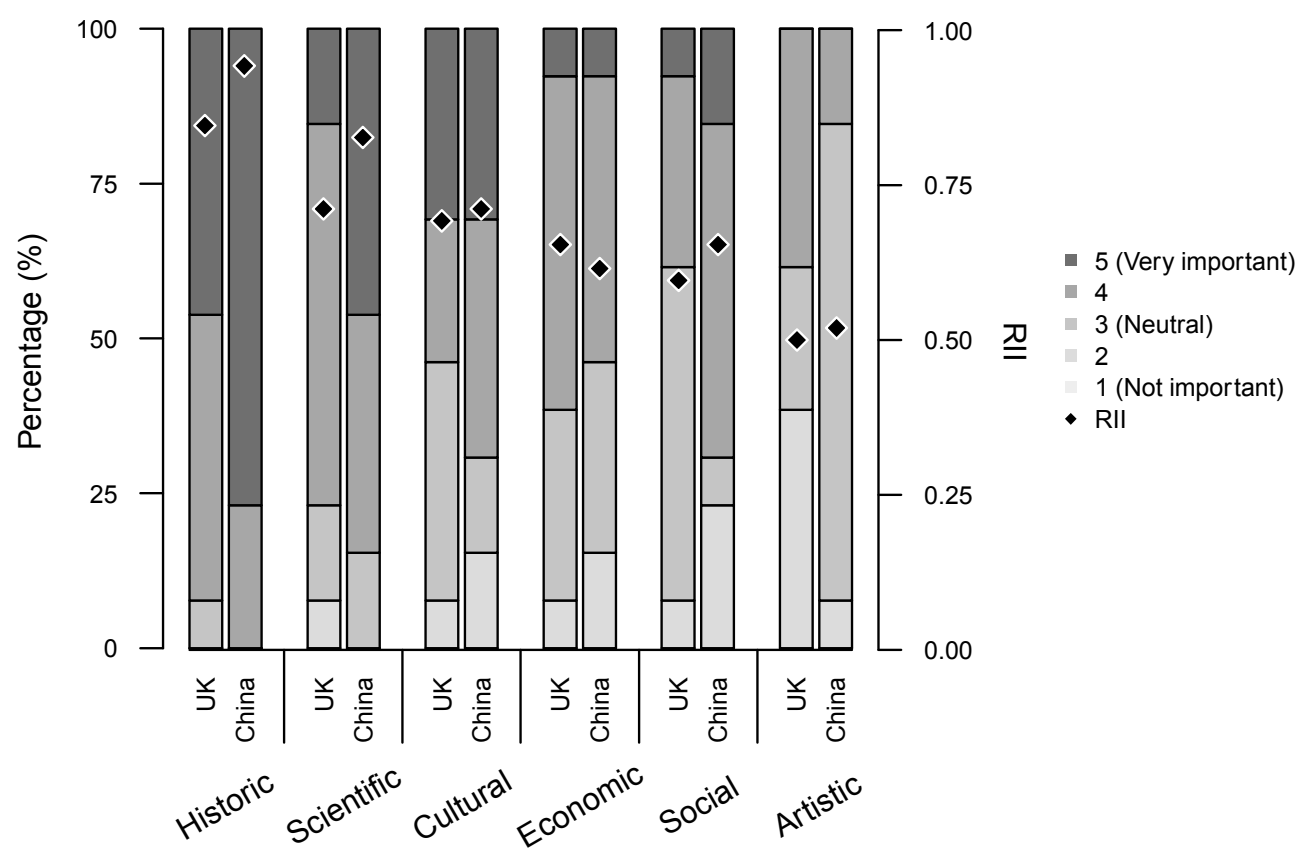

Figure 5. The historic scientific, cultural, economic, social and artistic values associated with Suoyang by UK and Chinese respondents.

In all cases except economic value, the Relative Importance Index (RII) showed that Chinese participants attributed a greater importance to each value (Figure 5). In discussion, Chinese participants shared knowledge that many UK based participants were unaware of, such as a Tang dynasty story where a Chinese General and his army were surrounded at the city by a Western army. When food ran out, they ate a plant called Suoyang to keep them strong and named the city after it.

The importance of economic value was debated. In the post-it note task, economic considerations had the greatest number of post-it notes votes in both the most and least important categories. Participants generally thought, in theory, economic value should not be important but in practice can help fund a site's general upkeep and conservation.

Many participants argued that values could not be viewed in isolation due to links and overlaps between value types. In addition, it was agreed that the value of Suoyang should be viewed within 
a wider context such as comparing it to the other sites which form the Silk Roads World Heritage site or across wider areas such as China or central Asia. Finally, it was stressed by all groups that understanding a site's value was crucial before any conservation strategy was designed or undertaken.

\subsubsection{Conservation Strategies}

For both Chinese and UK based respondents, the need for maintaining integrity and authenticity; having scientific research to underpin conservation; and having a site scale conservation strategy were the conservation attributes with the highest RIIs and all showed almost-if not complete-agreement between participants (Figure 6). In addition, most respondents preferred conservation strategies to use both scientific and local knowledge; innovative and traditional techniques; Western and Chinese conservation policies and conserve physical and intangible heritage.

a)

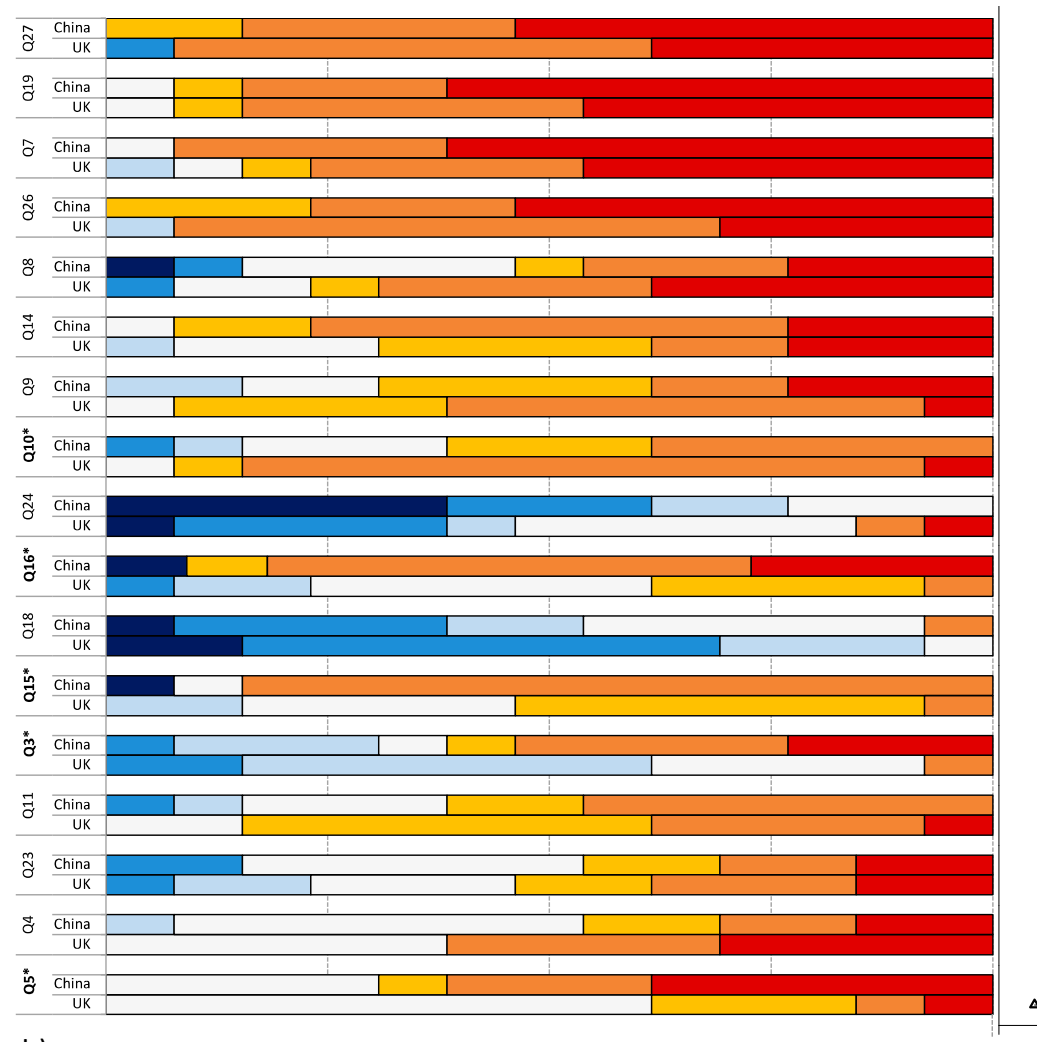

b)

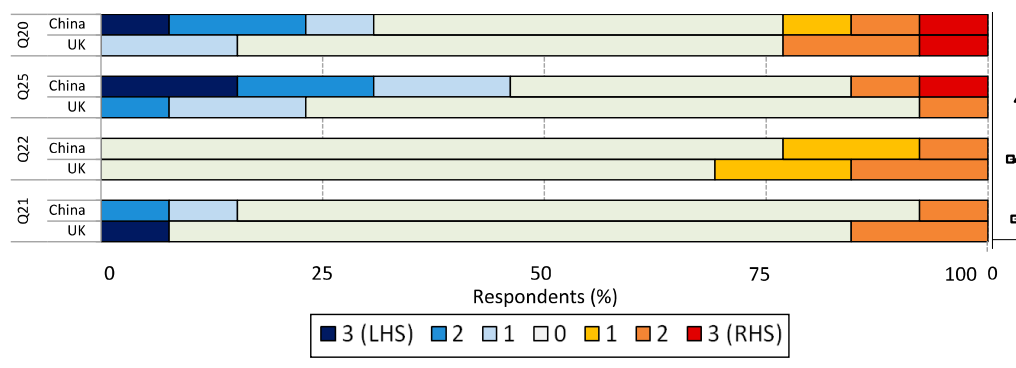

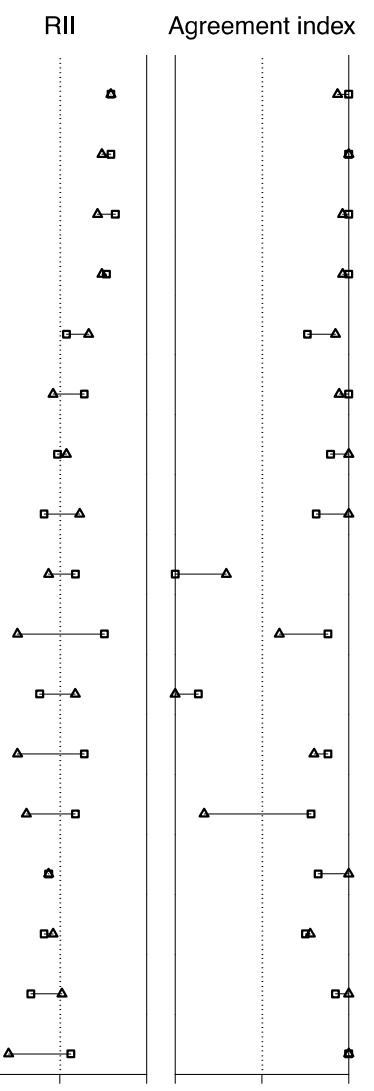

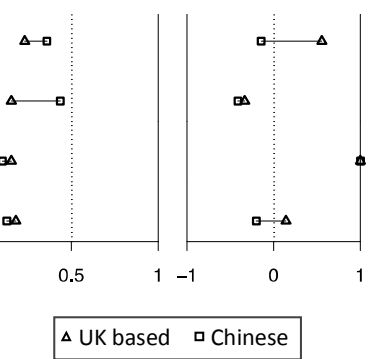

Figure 6. The responses for conservation attributes for Chinese and Western respondents of (a) true opposites and (b) false opposites along with their corresponding RII and Agreement Index values. Refer to Table 2 for Question numbers.

Responses from participants regardless of nationality or background expressed that scientific research should be embedded in conservation strategies and many wanted more scientifically informed 
site scale, preventative conservation to be used at earthen sites. These strategies were also viewed by participants as beneficial to maintaining Suoyang's authenticity and integrity as strategies would cover the whole site and could modify the environment rather than the site's physical structure. However, participants acknowledged the complexity of applying this in practice as many areas of Suoyang and other earthen sites, require urgent rescue treatments. In these situations, participants argued that treatments may be used without full scientific research and potentially at the detriment of the site's authenticity and integrity.

In addition, there was almost complete agreement that short term degradation should be minimized. However, minimizing short term degradation was more essential to UK based respondents than Chinese respondents. In the medium and long terms, there was complete agreement amongst UK based respondents that degradation should be minimized but notably less agreement amongst the Chinese respondents. This difference was significant at the medium term (Table 4, Q10). In discussions, the disjunct between practice and theory was again raised as, in principle, participants supported conservation strategies minimizing long term degradation but recognized the need for rescue conservation which can cause strategies to focus on short term degradation.

Table 4. $\mathrm{P}$ values (to 3 decimal places) for questions with significant differences between Chinese and UK based participants. Refer to Table 2 for Question Numbers.

\begin{tabular}{cc}
\hline Question Number & $p$ Value \\
\hline Q3 & 0.027 \\
Q5 & 0.041 \\
Q10 & 0.014 \\
Q15 & 0.002 \\
Q15b & 0.019 \\
Q16 & 0.002 \\
Q16b & 0.001 \\
\hline
\end{tabular}

There were slight preferences shown by Chinese respondents towards using scientific knowledge and the China Principles to inform conservation strategies and by UK based respondents towards using local knowledge and Western conservation principles. The preference held by UK based respondents for using Western principles was notably stronger than the Chinese respondents towards using the China Principles. Chinese respondents showed a stronger preference to conserve physical aspects of heritage sites than UK based respondents. This was similarly seen in the discussion where Chinese respondents reported that the conservation of physical features was a primary goal.

There were significant differences between the UK based and Chinese respondents over the amount of people hours they thought were needed for maintenance and installation (Table 4, Q15-16b). Having intensive people hours for both the maintenance and installation was more essential for Chinese than UK based respondents. Furthermore, when respondents were asked what they would consider as a minimal number of people hours and a cheap cost for installation and maintenance, there was a significant difference between the UK based and Chinese respondents, with Chinese respondents considering more people hours and higher costs to be considered as minimal and cheap than the UK based respondents. Chinese participants highlighted that in theory maintenance would be done daily on site but in practice there are not the resources allocated to make this possible.

In addition, there were also significant differences between the UK based and Chinese respondents over approaches to a conservation strategy's visibility and the number of parts. Chinese respondents would also prefer the strategy not to be visible whereas there was a preference for UK based respondents for the strategy to be visible. The Chinese respondents also showed a stronger preference towards a strategy having more component parts with UK respondents showing little preference. 


\section{Discussion}

\subsection{Policy and Practice}

Historic England's Conservation Principles and the China Principles provide a broadly similar approach to heritage conservation with regard to what heritage conservation aims to achieve, the importance of understanding the value of a heritage site, valuing authenticity and integrity and preferred conservation strategies. In contrast, there were many differences found between the practices of heritage conservation in the UK and China with differences of what authenticity is and who is able to participate [46-50]. This suggests that, at policy level, there is already the basis for a common language in heritage conservation between UK and China which could be applied directly to earthen heritage research. However, the differences found in practice suggest that further work needs to be undertaken to develop a meaningful common language at a practical level. As all heritage conservation is ultimately practical, for earthen heritage collaborations between the UK and China to be successful, further work is needed to understand why differences between policy and practice emerge and if these processes can be included within a common language to improve cross cultural understandings.

\subsection{Values}

The set of values in the China Principles were used in the co-created questionnaire to understand how participants valued Suoyang and earthen heritage. All participants at the workshop were used to attaching values to heritage sites but for many of the UK based participants the value types in the questionnaire were new. Furthermore, previous studies suggested that the emphasis in China on the deep cultural meaning and spiritual values of cultural sites which contrasted with the West's emphasis on the functional attributes of heritage sites [15] and the hierarchies of value imposed by Western countries resulted in differences in understanding of the concept of heritage value [44]. Consequently, the similarity between how Chinese and UK based participants valued Suoyang was unexpected but suggests that this transfer in understanding of value types across cultures is likely to have been aided by the overlap of some values in the China Principles' values with those presented by Historic England (Figure 4) and also by this study's approach to sharing knowledge: the co-creation of the questionnaire gave participants the opportunity to discuss and amend definitions of values before answering the questionnaires (Figure 3). This suggests the bilingual discussion-based method enables participants to go beyond an east/west divide by working together to engage critically with concepts from their own country and other countries and to use both in developing more nuanced understandings of the given concepts [11]. This study also demonstrates that locals and non-locals provide different lenses through which to view the importance of Suoyang and other earthen sites; when the understandings from these lenses are combined a fuller understanding of a site's value is achieved. Local knowledge has been argued to be vital in understanding the cultural and social values both in China and the UK $[48,51]$ and was similarly seen with the knowledge held by the Chinese participants in this study with for example the Chinese Army story, which outsiders may not be aware of or have access to the information. Non-locals can provide a set of understandings on what foreigners might value when visiting. For example, Suoyang was viewed as unusual and beautiful by many UK based participants but ugly and functional for many Chinese based participants. This demonstrates the need to view the site from multiple perspectives as something that is common or boring to one person may be beautiful and rare to someone else. Access to local and non-local knowledge and perspectives requires trust and mutual respect between both parties. This study achieved this between local and non-local heritage experts with accurate translation, explanations of what the knowledge will be used for and valuing opinions equally. Further work is needed to understand the opinions of other stakeholder groups at Suoyang.

It is also interesting to note that economic value is not in the China Principles or Historic England's Conservation Principles, despite both principles emphasizing site sustainability and role within the tourism industry. At this workshop, the tension between the ideal that economic value should not 
be viewed as important versus the reality that the economic value of a site helps fund conservation was expressed by both UK based and Chinese participants. In addition to common approaches, these common challenges could also be used as a basis for forming collaborations.

These findings show that heritage experts from countries with different histories regarding heritage conservation, which have different heritage conservation policies and past practices, can effectively come to a mutual understanding of a site's value, by discussing and debating issues and new concepts in a bilingual environment. It also shows how collaborations have the potential to enrich the value of earthen heritage sites with different groups identifying their own specific areas of value.

\subsection{Conservation Strategies}

This study found that Chinese and UK based heritage experts generally agreed that concepts and issues such as authenticity, integrity, scientific underpinning and conserving physical and intangible values of a site were the most important to consider when devising a conservation strategy for Suoyang. This is seemingly unsurprising as both English and Chinese policies stress the importance of these concepts and studies have found that in practice there is a similar emphasis on their consideration $[6,45,52]$. However, this study found that it is notable that there were compromises made by participants in how they would theoretically undertake conservation and what they are willing to accept in practice. For example, participants from both countries in theory would maintain authenticity by conserving present day materials, being minimally invasive and altering the environmental conditions. However, in practice, participants accepted that for some conservation such as rescue conservations, strategies may need to be applied to the physical structure of the wall. Similarly, for scientific underpinning, researchers theoretically wanted conservation strategies to be fully researched. However, in practice, due to a lack of historical data for earthen heritage, the large number of earthen sites in need of conservation and a lack of financial investment into earthen heritage, participants acknowledged that conservation strategies may not be fully researched. This suggests that for earthen heritage collaboration to be successful, all parties need to understand what each party considers as an ideal solution but also what they would be willing to compromise on to implement a strategy in practice. The similarities between the UK based and Chinese participants' approaches to earthen heritage conservation both in theory and practice suggest that there is common ground between these parties even when compromises have been taken into consideration.

The majority of Chinese and UK based heritage experts also agreed that having a site scale conservation strategy applied to areas of the site experiencing degradation and at risk of future degradation was important. Historic England's Conservation Principles does not provide guidance on spatial scales at which conservation should be undertaken but states that conservation strategies are only harmful if the significance of a site is eroded [36] (p. 43). In contrast, the China Principles states that intervention should be on areas of heritage at risk of degradation or areas most at need [37] (p. 68). This difference in findings between the Chinese participants and the China Principles indicates the presence of a Chinese Policy/Participant disagreement (see Figure 7). This could be because the China Principles are generalized for all immovable heritage sites and so does not specifically consider the vulnerability of earthen heritage to degradation. Furthermore, the practicalities of applying conservation strategies at a site scale should be considered within a collaboration. The complexity of site scale conservation mean that collaborations are likely to be needed for longer periods of time and also increases the number of potential misunderstandings between collaborators. However, the findings from this study have shown that complex problems can be effectively tackled with clear communication and equal treatment amongst members. 


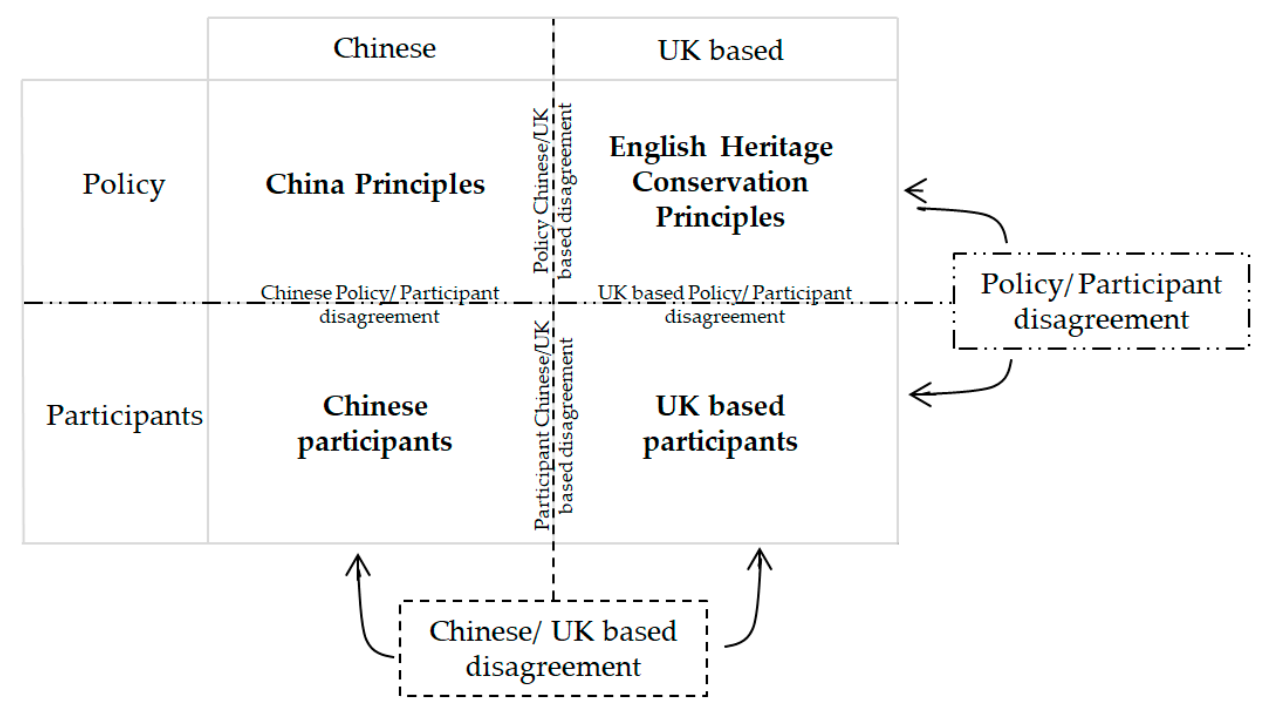

Figure 7. A diagrammatic representation of two types of disagreement that can occur when trying to find common ground for earthen heritage conservation between China and the UK: (i) Policy/Participant disagreement and (ii) Chinese/UK based disagreement. Where disagreements only applied to one row or column, they are referred to by the titles on the inside of the diagram for example, Chinese Policy/Participant disagreement.

This study also found that there are further challenges for collaboration as there are significant differences between UK based and Chinese respondents with issues such as minimizing degradation and the practicalities for implementing conservation strategies, even though the China Principles and Historic England's Conservation Principles are broadly similar. This difference between the UK based and Chinese participants indicates that for these issues there is a Participant Chinese/UK based disagreement (Figure 7). This could have occurred as many of the Chinese participants had implemented conservation strategies, including rescue conservation, on site but the UK based participants had limited on site experience. Therefore, the Chinese participants are likely to been more aware than their UK counterparts of the complexities and thus the resources needed for implementing a conservation strategy on site and the limitations of conservation strategies at reducing degradation. In addition, it is interesting that the importance of degradation over the three timescales remains relatively stable for the Chinese respondents but for the Western respondents there is a significantly lower importance placed on minimizing long term degradation. This could be a reflection of Historic England's Conservation Principles statement that the ability to judge the long-term impact of a strategy is limited on the UK based participants. These differences show that similarities in policies do not always translate into similar practices between heritage experts. This highlights the importance of being aware of participants' backgrounds and previous experience to understand how participant's previous experiences may feed into their future conservation practices.

Finally, this study found that there were also differences between the responses from UK based and Chinese respondents which reflect differences in policy and past practice. The stronger preference for Chinese respondents to preserve the physical structure of a wall could reflect the China Principles placing a larger emphasis on conserving tangible rather than intangible heritage compared to Historic England's Conservation Principles. Similarly, the difference in Chinese and UK based respondents towards the visibility of a conservation strategy could be caused by differing ideas of integrity and authenticity $[43,44]$. The UK based respondents' preference towards a visible strategy could be influenced by Historic England's Conservation Principles definition of integrity which is based around the idea of honesty and for conservation treatments to be able to be differentiated from the historic material. If visitors to a site are also able to differentiate between the treatment and historic material, the treatment needs to be visible. In the China Principles, conservation treatments are also supposed 
to be distinguishable from historic material (p. 45). However, as seen in practice with the different translations of authenticity, it is also common for sites to be restored back to an original state with limited emphasis placed on the differentiation between historic and new materials [45]. This suggests that in these cases both Policy/Participant and Chinese/UK based disagreements are present (Figure 7) and could pose the greatest challenge for finding common ground for earthen heritage conservation.

This study shows that even if countries' policies and practices have previously been similar, for collaboration it cannot be assumed that participants will follow their policy guidelines or past practices. Instead, the process for finding common ground for collaborations is specific to individual groups of people and individual earthen heritage sites. This study shows that establishing a bilingual environment where all participants are able to present their views can provide a pathway for discussion, debate and ultimately the potential for promoting and increasing the success of collaborations both for earthen heritage conservation and potentially many other areas of research.

\section{Conclusions}

This study compared heritage conservation policy, practice and heritage experts' opinions to assess the extent to which there is common ground between UK based and Chinese approaches to earthen heritage conservation. A bilingual workshop with discussion sessions and a co-created questionnaire were used to understand how Chinese and UK based heritage experts value earthen heritage sites and what they view as important properties for a conservation strategy. Suoyang Ancient City, China, was used a case study to focus discussions during the workshop.

This study found that for both UK based and Chinese heritage experts, historic value was the most important and artistic value the least important value for the earthen heritage site of Suoyang. It also found that concepts and issues of integrity, authenticity, scientific underpinning, the scale of the conservation strategy, conserving physical and intangible values of a site and methods used to undertake conservation were viewed as very important by both sets of experts. However, there were also some significant differences between the Chinese and UK based heritage experts, such as their approaches to installing and maintaining conservation strategies.

Overall, the similarities and differences in participant responses, policies and practice show the importance of acknowledging the wide array of approaches towards earthen heritage conservation. This study showed that to understand if two (or more) groups will be able to undertake successful collaboration, it is not enough to compare policies and past practices but that also the opinions of the specific people involved need to be considered. To enable these opinions to be honestly and openly expressed, this study has shown that a bilingual, workshop approach enabled respectful discussion and debate. The similarities between UK based and Chinese experts found in this study suggest similar groups of heritage experts could also use this process to find common ground which could be used as a basis for future collaborations. Undertaking a field based meeting could be a potential next step to further strengthen collaborations.

Author Contributions: Conceptualization, J.R. and H.V.; Data curation, J.R. and S.A.O.; Formal analysis, J.R.; Funding acquisition, H.V.; Investigation, J.R. and Y.W.; Methodology, J.R., Y.W. and H.V.; Project administration, H.V.; Resources, J.R. and Y.W.; Supervision, H.V.; Validation, J.R., Y.W., S.A.O. and H.V.; Visualization, J.R. and S.A.O.; Writing一original draft, J.R.; Writing—review \& editing, Y.W., S.A.O. and H.V.

Funding: This research was funded by UK Engineering and Physical Sciences Research Council (EPSRC) grant for the Centre for Doctoral Training Science and Engineering in Art, Heritage and Archaeology (EP/L016036/1) in association with the Getty Conservation Institute. The workshop was made possible by funding from the EPSRC Global Challenge Research Fund Institutional Sponsorship 2017.

Acknowledgments: We are grateful to all the participants in this study for sharing their knowledge and experience with us throughout this study. We are also grateful to Hong Zhang, Faguo He and Linyi Zhao for their assistance with translation and advice which allowed the workshop to run smoothly. We thank the two anonymous reviewers for their helpful feedback on this paper.

Conflicts of Interest: The authors declare no conflict of interest. 


\section{Appendix A}

Six question types were used in the questionnaire to address a range of questions.

1. Single choice tick box questions were used to understand the preferred choice of a respondent or to quantify/calibrate a concept.

2. Multiple choice tick box questions were used to understand the range of actions a respondent might choose.

3. A five-point Likert-type scale was used for the questions relating to value. The scale ranged from 1 (not important) to 5 (very important) with 3 as neutral. Intermediary numbers did not have word descriptions to produce more equal spacing between the numbers on the scale.

4. An adapted seven-point semantic differential/Likert-type scale with true opposites was used for questions relating to conservation strategies. Pairs of mutually exclusive words, such as "visible" and "not visible," were placed at the left and right ends of a horizontal scale. The scale ranged from 3 (left hand side concept is essential) to 0 (neutral) to 3 (right hand side concept is essential). As with the five point Likert-type scale, the intermediary numbers did not have word descriptions attached to them to produce more equal spacing between the numbers on the scale.

5. An adapted seven-point semantic differential, Likert-type scale with false opposites was also used for questions relating to conservation strategies. This differed from the previous question type as the pairs of words at the opposite ends of the scale were not mutually exclusive. These questions were included to force the respondents to think about which they cared about more. If both were of equal importance, they would choose " 0. "

6. Open questions were used to asking the respondents to describe their preferred conservation strategy. This allowed space for any comments not raised previously in the discussion to be expanded upon.

\section{Appendix B}

Calculation of RII and Agreement Index.

The Relative Importance Index (RII) was used to assess the strength of response participants attributed to a given question. It is calculated by:

$$
R I I=\frac{\Sigma w}{(A-Z) \times N}=\frac{0 n_{1}+n_{2}+2 n_{3}+3 n_{4}+4 n_{5}}{4 N}
$$

where $w$ is the weighting, $A$ is the highest score a respondent could give, $Z$ is the lowest score a respondent could give and $N$ is the total number of respondents. The highest score, $A$, needs to be offset by the lowest score, $Z$, so the scale for the scores starts at 0 . The equation above also gives an example of how the weighting $(w)$ is calculated for the 5 point Likert-type questions where, $n_{1}$ is the number of respondents for " 1, " $n_{2}$ is the number of respondents for " 2, " $n_{3}$ is the number of respondents for " 3, " $n_{4}$ is the number of respondents for " 4 " and $n_{5}$ is the number of respondents for " 5 ."

The Agreement Index was developed by the authors to calculate the agreement between respondents. The index was calculated by:

$$
\text { Agreement Index }=2\left(\frac{n_{1 R H S}+2 n_{2 R H S} \ldots+i n_{i R H S}}{i n_{i L H S} \ldots+2 n_{2 L H S}+n_{1 L H S}+n_{1 R H S}+2 n_{2 R H S} \ldots+i n_{i R H S}}\right)-1
$$

where $n_{1 R H S}$ is the number of respondents for " 1 " on the right hand side of the scale, $n_{2 R H S}$ is the number of respondents for " 2 " on the right hand side of the scale, $n_{i R H S}$ is the number of respondents for the highest score on the right hand side of the scale, $n_{i L H S}$ is the number of respondents for the highest score on the left hand side of the scale, $n_{2 L H S}$ is the number of respondents for " 2 " on the left hand side of the scale and $n_{1 L H S}$ is the number of respondents for " 1 " on the left hand side of the scale. Neutral responses were not included as they had not shown a preference to either side of the scale. 


\section{References}

1. Houben, H.; Balderrama, A.A.; Simon, S. Our earthen architectural heritage: Materials research and conservation. MRS Bull. 2004, 25, 338-341. [CrossRef]

2. Balderrama, A.A. The conservation of earthen architecture. Conserv. Getty Conserv. Inst. Newsl. 2001, $16,4-11$.

3. Twiss, K.C. The Neolithic of the Southern Levant. Evol. Anthropol. 2007, 16, 24-35. [CrossRef]

4. The World Heritage Programme on Earthen Architecture. World Heritage: Inventory of Earthen Architecture. 2012. Available online: http://unesdoc.unesco.org/images/0021/002170/217020e.pdf (accessed on 22 November 2017).

5. Correia, M.; Guerrero, L.; Crosby, A. Technical strategies for conservation of Earthen archaeological architecture. Conserv. Manag. Archaeol. Sites 2015, 17, 224-256. [CrossRef]

6. Zhu, Z.; Eckfeld, T. The development of conservation practices in China from the 1980s to the present. AICCM Bull. 2016, 37, 26-34. [CrossRef]

7. Matero, F.; Cancino, C. The conservation of earthen archaeological heritage: An assessment of recent trends. In TERRA 2000, Proceedings of the 8th International Conference on the Study and Conservation of Earthen Architecture, Torquay, Devon, UK, May 2000; James \& James: London, UK, 2000; pp. 11-21.

8. Correia, M. Conservation in Earthen Heritage: Assessment and Significance of Failure, Criteria, Conservation Theory, and Strategies; Cambridge Scholars Publishing: Cambridge, UK, 2016; ISBN 9781443889292.

9. Shao, M.; Li, L.; Wang, S.; Wang, E.; Li, Z. Deterioration mechanisms of building materials of Jiaohe ruins in China. J. Cult. Herit. 2013, 14, 38-44. [CrossRef]

10. Jun, Z. Comparison of Heritage Conservation Philophies in China and Other Countries. In International Principles and Local Practices of Cultural Heritage Conservation; ICOMOS China, Ed.; ICOMOS China: Beijing, China, 2014; pp. 40-61.

11. Winter, T. Beyond Eurocentrism? Heritage conservation and the politics of difference. Int. J. Herit. Stud. 2014, 20, 123-137. [CrossRef]

12. Qian, F. China's Burra Charter: The Formation and Implementation of the China Principles. Int. J. Herit. Stud. 2007, 13, 255-264. [CrossRef]

13. Forster, A.M.; Thomson, D.S.; Richards, K.; Pilcher, N.; Vettese, S. Western and Eastern building conservation philosophies: Perspectives on permanence and impermanence. Int. J. Archit. Herit. 2018, in press. [CrossRef]

14. Zhan, G. Viewing the China Principles in the International Context. In International Principles and Local Practices of Cultural Heritage Conservation; ICOMOS China, Ed.; ICOMOS China: Beijing, China, 2014; pp. 31-39.

15. Zhu, Y. Some thoughts on comparison of heritage conservation in historic cities in China and the West: A transcultural perspective. Southeast Cult. 2011, 221, 118-122.

16. Bin, J. Influence of the China Principles on Archeological Site Conservation in China. In International Principles and Local Practices of Cultural Heritage Conservation; ICOMOS China, Ed.; ICOMOS China: Beijing, China, 2014; pp. 183-193.

17. Elert, K.; Sebastián, E.; Valverde, I.; Rodriguez-Navarro, C. Alkaline treatment of clay minerals from the Alhambra Formation: Implications for the conservation of earthen architecture. Appl. Clay Sci. 2008, 39, 122-132. [CrossRef]

18. Elert, K.; Pardo, E.S.; Rodriguez-Navarro, C. Alkaline activation as an alternative method for the consolidation of earthen architecture. J. Cult. Herit. 2015, 16, 461-469. [CrossRef]

19. Zhang, H.-Y.; Zhu, S.-B.; Li, M.; Zhang, X.-C. Water Repellency of Monument Soil Treated by Tung Oil. Geotech. Geol. Eng. 2016, 34, 205-216. [CrossRef]

20. Selwitz, C.; Coffman, R.; Agnew, N. The getty adobe research project at Fort Selden III: An evaluation of the application of chemical consolidants to test walls. In 6th International Conference on the Conservation of Earthen Architecture; Agnew, N., Ed.; The Getty Institute: Los Angeles, CA, USA, 1990; pp. 255-260.

21. Selwitz, C. Saving the Fort Selden ruins: The use of a composite blend of chemicals to stabilize fragile historic adobe. Conserv. Manag. Archaeol. Sites 1995, 1, 109-116. [CrossRef]

22. $\mathrm{Li}, \mathrm{Z}$. Consolidation of a Neolithic earthen site with potassium silicate. In Proceedings of the 6th International Conference on the Conservation of Earthen Architecture: Adobe 90 preprints; Grimstad, K., Ed.; Getty Conservation Institute: Los Angeles, CA, USA, 1990; pp. 295-301. 
23. Oliver, A. Conservation of earthen archaeological sites. In Terra Literature Review: An Overview of Research in Earthen Architecture Conservation; Avrami, E.C., Guillaud, H., Hardy, M., Eds.; The Getty Institute: Los Anglese, CA, USA, 2008; pp. 80-96.

24. Alva, A.; Chiari, G. Protection and conservation of excavated structures of mudbrick. In Conservation on Archaeological Excavations, with Particular Reference to the Mediterranean Area, Centre for the Study of the Preservation and Restoration of Cultural Property; Stanley-Price, N., Ed.; ICCROM: Rome, Italy, 1995; pp. 101-112.

25. Chaudhry, C.; Sikka, S. Conservation treatments for earthen structures in the Western Himalayas of India. APT Bull. 2009, 40, 35-42.

26. Oliver, A.; Getty Adobe Project; Getty Conservation Institute; Museum of New Mexico. Fort Selden Adobe Test Wall Project: Phase I: Final Report; Getty Conservation Institute: Los Angeles, CA, USA, 2000.

27. Caperton, T. Fort Selden Ruins Conservation. In Proceedings of the 6th International Conference on the Conservation of Earthen Architecture: Adobe 90 preprints; Grimstad, K., Ed.; Getty Conservation Institute: Los Angeles, CA, USA, 1990; pp. 209-211.

28. Fodde, E.; Khan, M.S. Affordable Monsoon Rain Mitigation Measures in the World Heritage Site of Moenjodaro, Pakistan. Int. J. Archit. Herit. 2013, 1-22. [CrossRef]

29. Lister, R.H.; Lister, F.C. Aztec Ruins on the Animas, Excavated, Preserved and Interpreted; Western National Parks Association: Tuscon, AZ, USA, 1987.

30. Hughes, R. A review of works at the world heritage monument of moenjodaro, Pakistan. In Preserving Archaeological Remains In Situ; Corfield, M., Hinton, P., Nixon, T., Pollard, M., Eds.; Museum of London Archaeology Service: London, UK, 1998; pp. 26-30.

31. Li, Z.; Wang, X.; Sun, M.; Chen, W.; Guo, Q.; Zhang, H. Conservation of Jiaohe ancient earthen site in China. J. Rock Mech. Geotech. Eng. 2011, 3, 270-281. [CrossRef]

32. Chiari, G. Chemical surface treatments and capping techniques of earthen structures: A long-term evaluation. In Proceedings of the 6th International Conference on the Conservation of Earthen Architecture: Adobe 90 Preprints; Grimstad, K., Ed.; The Getty Institute: Los Angeles, CA, USA, 1990; pp. 267-273.

33. Warren, J. Conservation of Earth Structures; Butterworth-Heinemann: Oxford, UK, 1999.

34. Arzaga, A.G.; Baca, L.F.G.; Contreras, F.U. International Collaborations to Preserves Earthen Architectural Heritage. In TERRA 2008, Proceedings of the 10th International Conference on the Study and Conservation of Earthen Architecture; Rainer, L., Rivera, A.B., Gandreau, D., Eds.; The Getty Conservation Institute: Los Angeles, CA, USA, 2008; pp. 383-387.

35. Agnew, N.; Demas, M.; Sullivan, S. The development of the China Principles: A Review to Date. In International Principles and Local Practice of Cultural Heritage Conservation; ICOMOS China, Ed.; ICOMOS China: Beijing, China, 2014; pp. 11-30.

36. Drury, P.; McPherson, A. Conservation Principles Policies and Guidance for the Sustainable Management of the Historic Environment 2008; English Heritage: London, UK, 2008.

37. ICOMOS China. Zhongguo Wen Wu Gu Ji Bao Hu Zhun Ze= Principles for the Conservation of Heritage Sites in China, Rev. ed.; Wen wu chu ban she: Beijing, China, 2015.

38. Sodangi, M.; Khamdi, M.F.; Idrus, A.; Hammad, D.B.; AhmedUmar, A. Best Practice Criteria for Sustainable Maintenance Management of Heritage Buildings in Malaysia. Procedia Eng. 2014, 77, 11-19. [CrossRef]

39. Zhu, G. China's architectural heritage conservation movement. Front. Archit. Res. 2012, 1, 10-22. [CrossRef]

40. Winter, T. Heritage conservation futures in an age of shifting global power. J. Soc. Archaeol. 2014, 14, 319-339. [CrossRef]

41. Zhou, L. Thirty Years of Chinese Cultural Heritage Protection. Conserv. Archit. Herit. 2008, 12, 1-5.

42. Starn, R. Authenticity and historic preservation: Towards an authentic history. Hist. Hum. Sci. 2002, 15, 1-16. [CrossRef]

43. Xu, H.; Wan, X.; Fan, X. Rethinking authenticity in the implementation of China's heritage conservation: The case of Hongcun Village. Tour. Geogr. 2014, 16, 799-811. [CrossRef]

44. Zhu, Y. Cultural effects of authenticity: Contested heritage practices in China. Int. J. Herit. Stud. 2015, 21, 594-608. [CrossRef]

45. Lu, Z. Evolution of Cultural Heritage Conservation Philosphy Through the Lens of Revised China Principles. In International Principles and Local Practices of Cultural Heritage Conservation; ICOMOS China, Ed.; ICOMOS China: Beijing, China, 2014; pp. 1-10. 
46. Han, F.; Yang, Z.; Shi, H.; Liu, Q.; Wall, G. How to Promote Sustainable Relationships between Heritage Conservation and Community, Based on a Survey. Sustainability 2016, 8, 886-896. [CrossRef]

47. Fan, L. International influence and local response: Understanding community involvement in urban heritage conservation in China. Int. J. Herit. Stud. 2014, 20, 651-662. [CrossRef]

48. Lui, T. China's Current State and Future Challenges for the Practice of Public Participation in Cultural Heritage Conservation. In International Principles and Local Practices of Cultural Heritage Conservation; ICOMOS China, Ed.; ICOMOS China: Beijing, China, 2014; pp. 225-241.

49. Pendlebury, J.; Townshend, T. The Conservation of Historic Areas and Public Participation. J. Archit. Conserv. 2014, 5, 72-87. [CrossRef]

50. Townshend, T.; Pendlebury, J. Public participation in the conservation of historic areas: Case-studies from north-east England. J. Urban Des. 1999, 4, 313-331. [CrossRef]

51. Jokilehto, J. Engaging conversation: Communities, place and capacity building. In Heritage, Conservation and Community: Engagement, Participation and Capacity Building; Chitty, G., Ed.; Routledge, Taylor \& Francis Group: New York, NY, USA; London, UK, 2017; pp. 17-34.

52. Wang, X. Conservation and management practices of the Mogao grottoes based on the principles for the conservation of heritage sites. In International Principles and Local Practices of Cultural Heritage Conservation; ICOMOS China, Ed.; ICOMOS China: Beijing, China, 2014; pp. 154-165.

(c) 2018 by the authors. Licensee MDPI, Basel, Switzerland. This article is an open access article distributed under the terms and conditions of the Creative Commons Attribution (CC BY) license (http://creativecommons.org/licenses/by/4.0/). 